\title{
The complexity of immune cell landscape in hepatocellular carcinomas with different risks-reply letter
}

\author{
Xiaofeng Tang", Zheyue Shü, Shusen Zheng \\ Department of Hepatobiliary \& Pancreatic Surgery, the First Affiliated Hospital, College of Medicine, Zhejiang University, Hangzhou, China \\ "These authors contributed equally to this work. \\ Correspondence to: Shusen Zheng. Department of Hepatobiliary \& Pancreatic Surgery, the First Affiliated Hospital, College of Medicine, Zhejiang \\ University, No. 79 Qingchun Road, Hangzhou, China. Email: shusenzheng@zju.edu.cn. \\ Provenance and Peer Review: This article was commissioned and reviewed by the Guest Section Editor Rui Liao (Department of Hepatobiliary \\ Surgery, The First Affiliated Hospital of Chongqing Medical University, Chongqing, China). \\ Response to: Ocker M. Dissecting the immune cell landscape in hepatocellular carcinoma-are we understanding complexity? Ann Transl Med \\ 2020;8:666.
}

Submitted Apr 10, 2020. Accepted for publication May 11, 2020.

doi: $10.21037 /$ atm-2020-92

View this article at: http://dx.doi.org/10.21037/atm-2020-92

Thank you for the invitation to respond to the editorials by Matthias Ocker on our recently published paper "Clinical significances of immune cell landscape in hepatocellular carcinoma (HCC) patients with different degrees of fibrosis". Our studies revealed that the fraction of resting mast cells and activated natural killer (NK) cells were significantly different between HCC patients with different fibrosis degree. Meanwhile, the genes participating those immune function and correlated with patients' overall survival and relapse-free survival were identified. The results suggested that PVRIG involved in T cell CD8 ${ }^{+}$ infiltration and NK cells is significantly positive associated with well-known checkpoint molecules (1).

In our studies, 212 HCC samples with fibrosis Ishak score from TCGA dataset were used. According to the editorials, we investigated the TNM stage, specimen collection method and virus infection of these samples. The numbers of HCC samples in stage I, stage II and stage III/IV are 108 (50.94\%), 51 (24.06\%) and $42(19.81 \%)$, respectively. Most of HCC samples were in the early disease stages and $202(95.28 \%)$ samples underwent curative surgery. Meanwhile, 90 (42.45\%) samples were infected with viral hepatitis and the TCGA clinical information were not described whether the samples were with nonalcoholic fatty liver disease (NAFLD). Due to the sample sizes and bias in different TNM stages, our results may not be entirely representative for real HCC samples.
Furthermore, we have tried to find an independent dataset to validate our results in the database GEO (https://www. ncbi.nlm.nih.gov/geo/) and ArrayExpress (https://www.ebi. ac.uk/arrayexpress/). Unfortunately, the expression profile with information of fibrosis degree and outcomes was not found. To investing the immune cell landscape in HCC with various fibrosis degrees and the underlying etiologies, there are lots of works to do in future.

Immune checkpoint blockade (ICB) has been reported to reactivate the antitumor immune response through blocking the inhibitory immune system (2). Immune checkpoint inhibitors are expressed primarily by $\mathrm{T}$ cells (for example, CTLA4, PD-1, HAVCR2 and LAG3) or by the tumor and other immune cells (for example, PD-L1). Right now, some inhibitors of CTLA4, PD-L1 and PD-1 have been used in kinds of solid cancers, including HCC (3). Two clinical trials in HCC, named CheckMate040 and Keynote224, has been reported by using nivolumab and pembrolizumab respectively $(4,5)$. Both of these trials suggested more clinical benefit compared to sorafenib treatment in advanced HCC. Right now, the response rate for single-agent ICB is approximate $15-20 \%$ in the treatment of HCC. What's more, $15-25 \%$ of these ICBtreated patients has experienced $3 / 4$ treatment or immunerelated adverse events (3). So, deeply understanding of molecular mechanism of immunotherapy and predictive biomarkers of response is a difficult challenge for improved 
clinical benefit to the HCC patients.

Previous studies have been revealed that tumorinfiltrating lymphocytes (TILs), including $\mathrm{CD}^{+} \mathrm{T}$ cells, are resulted in better prognosis of HCC (6). Recently, B cells and tertiary lymphoid structures associated with survival and immunotherapy response in sarcoma (7). Melanoma (8) and renal cell carcinoma (9) were also been reported. Our studies tried to reveal the differences of immune cell fractions in HCC patients with different fibrosis degrees and to select possible targets for improving immunotherapy. Our results suggested that, PRIVG, as a novel biomarker, is significantly associated with survival which is expressed on $\mathrm{T}$ cells and inhibiting $\mathrm{T}$ cell receptor-mediated signals. The results of Person correlation coefficient found that PVRIG is significantly positive related (R: $0.35-0.67$ ) with other checkpoint molecules, such as PDCD1, CTLA4 and Teff gene signatures. With the novel expression profiles and novel methods to quantify and analysis the immune landscape of HCC, more and more biomarkers could be identified. The response rate of immunotherapy could be raised and clinical outcomes could be better in feature.

\section{Acknowledgments}

Funding: This work was supported by the Zhejiang Natural Science Foundation (grant number LY16H160021), the Public Welfare Technology and Social Development Project of Zhejiang Provincial Bureau of Science and Technology (grant number 2017C33069), the Public Welfare Technology of Zhejiang Provincial Bureau of Science and Technology (grant number LGF19H030017).

\section{Footnote}

Conflicts of Interest: All authors have completed the ICMJE uniform disclosure form (available at http://dx.doi. org/10.21037/atm-2020-92). The authors have no conflicts of interest to declare.

Ethical Statement: The authors are accountable for all aspects of the work in ensuring that questions related to the accuracy or integrity of any part of the work are appropriately investigated and resolved.

Open Access Statement: This is an Open Access article distributed in accordance with the Creative Commons Attribution-NonCommercial-NoDerivs 4.0 International License (CC BY-NC-ND 4.0), which permits the non- commercial replication and distribution of the article with the strict proviso that no changes or edits are made and the original work is properly cited (including links to both the formal publication through the relevant DOI and the license). See: https://creativecommons.org/licenses/by-nc-nd/4.0/.

\section{References}

1. Tang $X$, Shu Z, Zhang W, et al. Clinical significance of the immune cell landscape in hepatocellular carcinoma patients with different degrees of fibrosis. Ann Transl Med 2019;7:528.

2. Wei SC, Duffy CR, Allison JP. Fundamental Mechanisms of Immune Checkpoint Blockade Therapy. Cancer Discov 2018;8:1069-86.

3. Tai D, Choo SP, Chew V. Rationale of Immunotherapy in Hepatocellular Carcinoma and Its Potential Biomarkers. Cancers (Basel) 2019;11:1926.

4. El-Khoueiry AB, Sangro B, Yau T, et al. Nivolumab in patients with advanced hepatocellular carcinoma (CheckMate 040): an open-label, non-comparative, phase $1 / 2$ dose escalation and expansion trial. Lancet 2017;389:2492-502.

5. Zhu AX, Finn RS, Edeline J, et al. Pembrolizumab in patients with advanced hepatocellular carcinoma previously treated with sorafenib (KEYNOTE-224): a non-randomised, open-label phase 2 trial. Lancet Oncol 2018;19:940-52. Erratum in: Correction to Lancet Oncol 2018; 19: 940-52. Lancet Oncol. 2018 Sep;19(9):e440.

6. Gabrielson A, Wu Y, Wang H, et al. Intratumoral CD3 and CD8 T-cell Densities Associated with Relapse-Free Survival in HCC. Cancer Immunol Res 2016;4:419-30.

7. Petitprez F, de Reyniès A, Keung EZ, et al. B cells are associated with survival and immunotherapy response in sarcoma. Nature 2020;577:556-60.

8. Cabrita R, Lauss M, Sanna A, et al. Tertiary lymphoid structures improve immunotherapy and survival in melanoma. Nature 2020;577:561-5. Erratum in: Nature. 2020 Apr;580(7801):E1.

9. Helmink BA, Reddy SM, Gao J, et al. B cells and tertiary lymphoid structures promote immunotherapy response. Nature 2020;577:549-55.

Cite this article as: Tang $\mathrm{X}$, Shu Z, Zheng S. The complexity of immune cell landscape in hepatocellular carcinomas with different risks—reply letter. Ann Transl Med 2020;8(11):729. doi: $10.21037 / \mathrm{atm}-2020-92$ 